\title{
Control of Yam Rot Using Chromoleana Odourata and Moringa Oleiferia
}

\author{
Enyiazu Franca Adanne \\ Faculty of Education, Southwest University, No. 2 tianshang road, Beibei district, \\ Chongqing 400715, P. R. China
}

\begin{abstract}
The study investigated the control Of Yam rot using Chromoleana odourata and Moringa Oleiferia. Spolt yam was inoculated into a prepared culture media after which the growth of the fungi observed were isolated and subculture to get a pure culture. The pure culture was then treated with the extract from Chromoleana Odourata and Moringa Oleiferia. From the treatment given to the isolated fungi (fusarium specie and Aspergillus specie etc.) it was observed that the extract had a significant effect on the growth of the rot fungi. It was based on this that the study recommended that farmers should use bio-fungicide from C.odorata and M.oliefera in the control of yam rot fungi. Keywords: Control of yam rot, growth of rot fungi, chromoleana odourata, moringa oleiferia

DOI: $10.7176 / \mathrm{JNSR} / 13-6-03$
\end{abstract}

Publication date:March $31^{\text {st }} 2021$

\section{Introduction}

Yam belongs to the genus Dioscorea in the family Dioscoreacea and is one of the most important staple foods in the world, especially some parts of Tropics and Subtropics (Okigbo, et al,2015). The edible varieties of yam are important food crops and serve as an important carbohydrate staple for millions of people in both the Tropical and Subtropical countries Africa, countries like Nigeria. The FAO (2011) estimated that the world production is around 20 million ton per year. Nigeria alone produces three quarter of the world total output of yams. Okigbo et al (2015) noted that of the ten cultivated species, the six most important in Nigeria are Dioscorea rotundata Poir (White yam), D. cayenensis Lam (yellow yam), D. alata L. (water yam), D. dumetorum (cluster or bitter yam), D. esculenta loir bark (Chinese yam) and D. Builbifera L. (aerial yam). Despite the importance of yam as a food source, it plays significant role in socio-cultural lives of some yam producing regions. The ritual and superstition often surrounding yam and utilization in West Africa is a strong indication of the antiquity of use of this crop (Ogbo \& Agu, 2014).

Yam tubers are of a very high value, as in food, where it is a major source of carbohydrate, minerals of calcium, phosphorus, iron and vitamins such as riboflavin, thiamine and vitamins B and C (Ogbonnaya,2013). Although yams are grown throughout Africa, including countries like Cameroon, Togo, Ghana, Nigeria and Ivory Coast. Nigeria is said to be the world's largest producer of yam accounting for over 70-76 percent of the world total output (Frank and Kingsley, 2014a). FAO reported that Nigeria alone in 1989 produced 18.3 million tonnes of yam from 1.5 million hectares, representing 73.8 percent of 28.8 million tonnes of yams produced in Africa.

Despites the importance and role played by this food staple, yam tubers have face major problems of rot diseases. Rot is a major factor limiting the post-harvest life of yams and losses can be very high. Losses due to post harvest rot significantly affect farmers' and traders' income, food security and seed-yams stored for planting. The quality of yam tubers is affected by rots which makes then unappealing to consumers (Ogbo and Agu, 2014; Agu et al., 2015). Losses of yams in storage mostly to rot are considered to be heavy in Nigeria; as a result, the demand for yam tubers has always exceeded its supply (FAO, 2010). Statistics have shown that an average of over $25 \%$ of the yield is lost annually to diseases and pests (FAO, 2010). Over $50 \%$ of the yam tubers produced and harvested in Nigeria are lost in storage. Most rots of yam tubers are caused by pathogenic fungi such as Aspergillus flavus, Aspergillus Niger (Tiegh), Fusarium oxysporum, Fusarium solani, Botryodiplodia theobromae, Penicilllium chrysogenum, Rhizoctonia spp, Penicillium oxalicum, Trichoderma virideand Rhizopus nodosus (Frank and Kingsley, 2014; Agu et al., 2014).

Microbial deterioration of yam starts in the soil reducing its capacity to germinate and its survival in the field and then progressed in storage which occur when infected tubers do not have any sign of external symptoms (Aidoo, 2017). The incidence of rotting varies with the species and with varieties within each species of yam. Nwankiti (2016) reported that rot vary due to variations in the distributions of the microorganisms and does related to the soil mineral status because the differences in the mineral status are not known to be correlated with the type of organism isolated nor total percentage of rot. Due to this deteriorating effect of rot on yam has warrant the adoption of several methods for controlling losses due to post harvest disease of yam; these include the use of chemicals, biological method of control, curing uses of natural plant extracts, as reported by Amusa et al., (2013). Because of the low capital income of farmers in Nigeria and lack of expertise in the safe handling of chemical, farmers resorted to the method of crop rotation, fallowing, planting of healthy material and destruction of infected crop cultivars in controlling the diseases of yam tubers (Nwankiti, 1982). Though chemical method of control has helped to reduce the rate of storage losses and also increases yield obtained, but the problem arising with the use 
of chemicals is that it is expensive, cause environmental pollution and may also induce pathogen resistance. Therefore, Biological control method has been preferred in some cases because it is selective with no side effect and cheap. This is why the use of plants phytochemicals with antimicrobial activities are advocated to be used in the control of diseases in yam, cowpea, rice, etc. (Bediako et al., 2017). The advantages of these natural plant products include its local availability, has little or no toxicity to humans and simple preparation procedures (Omaka,2012). Among these plants are the peel extract of water yam (Dioscorea alata). Due to the fact plant extract has being noted to have microbial effect on the activity and growth of microorganisms capable of causing rot warrant the study into investigating the control of yam rot using different plant extracts.

The study will significantly provide more knowledge on the plant extract that are mostly affect against yam rot diseases and will expose farmers to the usefulness of this biological methods of yam rot control so that they can adopt and use them for effective yam rot control. The study will also benefit them as the application of the findings of the study will enable them increase the level of income, reduce expose to health problems caused by the use of synthetic chemicals used in the control of rot diseases. The study will further benefit future researchers as it will serve as source of material and references for future related studies.

The aim of the study is to investigate plants extracts that effectively control yam rot diseases. Specifically, the objectives of the study will be to isolate and identify yam rot organisms and the effect of plant extracts such as Chromoleana odourata and Moringa oleiferia on the organisms. It will also ascertain the most effective plant extract against yam rot disease.

\section{Literature Review}

Yam (Dioscorea spp) is an economically important food crop in most tropical West African countries such as Nigeria (Evans, et al 2014). After cassava, yam is the second most important tuber (Adegbite et al.,2016). This is the reason why its important yam rot disease problem is fully addressed in other provide good source of food that will provide fibre, carbohydrate, vitamin $\mathrm{C}$ and other essential mineral for man (Polycarp et al.,2012). Furthermore, yam is also good source of secondary metabolites such as steroidal saponins, diterpenoids, and alkaloids which have been exploited for pharmaceutical products (Mignouna et al.,2009).

There are 600 species of yam (Dioscorea spp) and they are regularly cultivated for food Dioscorea rotundata and D.cayenensis (both known as Guinea yam) are the most popular and economically important yam in West central Africa where they are found to be indigenous (Quain et al.,2011). While Dioscorea alata which is one of the species of yam is the most widely distributed species globally. The consumer demand for yam is very high in sub-Saharan Africa. Unfortunately, yam production is decreasing due to factors such as yam rot diseases, such as diseases caused by nematodes, pests, fungi diseases among others (Evans et al., 2014).

According to Omaka (2012) some of the major microorganism causing diseases rots are Aspergillus flavus Lark ex Fr., Aspergillus niger Van Tiegh, Botryodiploidia theobronmae Pat, Fusarium Oxysporum Schlecht ex Fr., Fusarum solani (Mart.) Sacc., Pencillium chrysogenum Thom Rhizoctonia sp., Penicillum oxalicum, Currie and Thom, Trichoderma viride Pers. ex S. F. Gray and Rhizopus nodosus N' amyslowski. These microorganisms produce mycotoxins which are toxic secondary metabolites produced by organism of the fungus kingdom which affect the yam and causes rot. These toxic chemicals produced by fungi are readily colonized crops (Turner, et al., 2009). They are toxic chemical products produced by fungi that readily colonize crops. One mould species may produce many different mycotoxins and / or the same mycotoxin as another species. Where conditions are right, fungi proliferate into colonies and mycotoxin levels become high (Ogunleye, Akin, Ayansola \& Oyeronke,2014). The production of toxins depends on the surrounding intrinsic and extrinsic environments and the toxins vary greatly in their severity, depending on the organism infected and its susceptibility, metabolism, and defence mechanisms.

Temperature treatments, such as cooking and freezing do not destroy (Ogunleye et al,2014). Major groups of mycotoxins according to Ogunleye, Akin, Ayansola \& Oyeronke, (2014) include: aflatoxins (produced by Aspergillus species of fungi), Ochratoxins, Citrinins (both produced by Penicillium and Aspergillus species), Patulin (produced by Aspergillus, Penicillium, and Paecilomyces fungal species.), beauvercin and enniatins butenolide, equisetin and fusarins (produced by Fusarium species.)

Yin, et al., (2018) posit that the umbrella term aflatoxin refers to four different types of toxins produced, which are B1, B2, G1 and G2. from seedling stage, yam is prone to infection through harvesting and even after harvesting in storage (Amusa et al., 2013). On the other hands, other causes of storage losses of yam tubers include: sprouting, transpiration, respiration, rot due to mould and bacteriosis, insects' nematodes and mammals.

One major constraint to yam production worldwide is post-harvest rot which may be either physiological or microbial (Otoo, et al., 2011). Ricci, et al. (2010) estimated microbial post-harvest losses in yam at $40 \%$ while Ikediugwu (2013) indicated that between 20 and 39-5\% of stored tubers may be lost to decay. For Coursey, (2009) the principal factors responsible for yam losses during storage are: the natural metabolic processes of the dormant tubers, which result in the conversion of starch of the tuber into carbon (iv) oxide and water; evaporation of water from the tuber; sprouting; and infection by various fungi which decay the tuber. 
Losses in yams in storage mostly to rot are considered to be heavy in Nigeria. These losses are pathological problem of yam tubers brought about by bacteria, fungi and nematodes (Ogunleye et al,2014). The losses cause by rot disease on yam are estimated to be 10-15\% (Ogunleye et al,2014). Most of the pathogens of yam tuber are soil borne, but manifestations of the tuber disease are observed mostly during storage. It has been estimated that an average of over $25 \%$ of the yield of yam is annually lost due to disease and pest (Ogunleye et al,2014). Okigbo, (2005) in Ogunleye et al, (2014). reported that agents causing disease reduce the quality of yam produce and its quality as well making it unappealing to consumers. The entry of rot pathogens in yam occurs through wounds or cuts and natural openings on the surface of the tubers (Ogunleye et al,2014). Several pathogenic fungi have been found associated with yam, causing diseases such as anthracnose, leaf spots and blight, as well as rotting of yam tubers (IITA, 2011).

\subsection{Efficacy of Plant Extract on Rot Organisms}

Successes have been recorded in the use of plant extracts such Chromolaena odorata and or Moringa oleifera to control fungal pathogens (Okigbo et al., 2010; Devendra et al., 2011). Aman and Rai (2015) reported antifungal activity of plant extracts against yellow sigatoka disease causing Mycosphaerella musicola in banana plantations. The antifungal activity of methanol extracts of Leonotis nepetifola L. and Ocimum gratissimum L. against asochyta blight (Phoma exigua) on french bean was also reported by Ochola et al. (2015) the biological activity of plant extracts is mainly as a result of the phytochemical constituents they contain. Leaf extracts of C. odorata and M. oleifera contain phytochemicals which offer an enormous potential as biocontrol agents of pathogens and a source of antimicrobial agents of therapeutic importance. It has been shown that M. oleifera leaf extract has antibiotic and antifungal properties against a wide range of pathogens like Escherichia coli, Pseudomonas aeruginosa, Staphylococcus aureus, Streptococcus pyogenes, Aspergillus niger and Candida albicans (Devendra et al., 2011). According to Ijato et al (2010), leaf extract of C. odorata is effective in the control of fungal pathogens of diseased tomato and yam infected with Aspergillus niger, Fusarium oxysporum, Rhizopus stolonifer and Geotrichum candidium.

From the study of Chiejina \& Onaebi (2016) ethanolic extracts of Chromolaena odorata and Moringa oleifera were found to be fungitoxic on the mycelial growth of the rot fungi. The disease development of Geotrichum candidum was inhibited by the plant extracts and benlate solution. The inhibitory effects of the plant extracts increased as the concentrations increased. The study further showed that Moringa oleifera extracts exhibited higher inhibitory effects than C. odorata at all the concentrations except at the lowest concentration of $20 \mathrm{mgmL}$. The results revealed that both plant extracts produced significant $(\mathrm{p}<0.05)$ levels of inhibition of mycelial growth of R. stolonifer at the various concentrations. Chiejina \& Onaebi (2016) study also showed the ethanolic extracts of $\mathrm{M}$. oleifera and $\mathrm{C}$. odorata at $100 \mathrm{mg}$ mLG1 concentration gave 100 and $66.6 \%$ inhibition on A. niger respectively.

Moringa oleifera extracts is most effective in arresting disease development and this compared very well with benlate at higher concentrations. The effects of the ethanolic leaf extracts and benlate solution on the mycelial growth of Fusarium oxysporum was significantly different $(p<0.05)$ for all the concentrations.

Investigation on the antifungal properties of A. indica, M. oleifera, C. papaya and A. sativum on the growth of isolates of yam rot organism such as Aspergillus flavus shows that these plants' crude extract possesses some inhibitory components which cause significant reduction in mycelial growth of the fungus (Tijjani et al,2014). Akpa et al., (2010) also reported a significant inhibitory property of neem (A. indica) extracts on mycelial growth of Colletotrichum graminicola; Amuchi (2013) found that the extracts of Ocimum gratissium reduced the radial growth of Rhizopus spp, just as Ebele (2011) found that the extracts of C. papaya reduced the radial mycelial growth of Aspergillus niger, Fusarium solani and Botryodipdia theobromae. The effectiveness of plants extracts depend on the nature and amount of biologically active ingredients it contains. Increase in the concentrations of the plant seed/bulb/leaves extracts correspondingly decreased radial growth of A. flavus and weight loss of tomato fruit. Increasing concentrations of these extracts implied an increase in the active ingredients of the solutions which act on the fungus thereby affecting its physiological processes and consequently lowering the growth of the fungus. The optimum concentration for the control of A. flavus as revealed by this study is 1:15 and 1:20 ME/water of E.N.S.O and 40 and $50 \mathrm{~g} / 250 \mathrm{mls}$ of A.G.B.E and A.M.S.E. The study therefore confirmed and established these antifungal activities of these plant crude extracts, which are interestingly systemic in action and can be used or applied as post-harvest tuber treatment against fruit rot in both yam and tomato rot caused by A. flavus. Udo et al. (2011) study also showed that plant extracts inhibit growth and sporulation of fungal pathogens on Ipomea batatas and Diocorea spp by garlic extracts; Okigbo (2009) reported that the use of Xylopia aethiopica and Zingiber officinale control yam tuber rot caused by F. oxysporum, A. niger and A. flavus; while Amienyo et al. (2017) reported that Z. officinale, Annona muricata, Gacinia cola, Alehornea cordifolia, Allium sativum controls wet rot on sweet potatoes caused by rot fungal pathogens.

Abdul-Aziz and Younes (2010) on the used Cinnamomum verum (Pimpinella anisum L.) black seed (Ngelia sativa L.) and clove (Syzygium aromaticum L. Merr and Perry) against Pea (Pisum sativum L.) root rot fungus 
(Rhizoctoni solani); they noted from their study that the extracts of these palnt has inhibitory activities against rot organism.Tijjani et al. (2010) use neem and moringa seed extracts against potato wet rot caused by R. stolonifer and found that it control organisms causing rot while Ijato et al., (2010) reported that A. indica and Chromolacna adorata is effect of the control against post-harvest and transit rot of tomato and Ebele (2011) observed in her study that the use of C. papaya, C. adorata and Acalypha ciliata control pawpaw fruit rot fungi.

Chiejina \& Onaebi (2016) reported that organisms associated rot in tubers and fruits are Geotrichum candidum, Mucor micheli, Rhizopus stolonifer, Aspergillus niger and Fusarium oxysporum. These organisms according to Onyeke and Ugwoke,( 2011); Chiejina and Onaebichiemeka, (2013) have been associated with postharvest rot of fruits. Rotting may probably start in the soil and progress in storage. This may happen when infected fruits do not show perceptible external symptoms (Chiejina \& Onaebi ,2016). Some of these pathogens like R. stolonifer and M. micheli produce germination of Fusarium oxysporum which is formerly reported to be inhibited by extracts of C. odorata (Okoi and Udo, 2010).

Dwivedi and Sangeeta (2015) in their study also reported the inhibition of the radial growth of Fusarium oxysporum f. sp. ciceri by some medicinal plant extracts in which M. oleifera was among. The inhibitory effect gradually increased with increase in the concentration of the extracts. This observation supports the report of Daouk et al (2009) that the reduction in microbial population depends on the concentration of the extracts and that high concentrations can completely inhibit the growth of microorganisms. Omaka (2012) in his study showed that the use of Chromolean odorata has inhibitory effect on the growth of rot organism such as fussarium spp and Aspergillus spp while Suleiman and Emua (2009) observed toxicity of plant extracts at higher concentrations. According to Suleiman and Emua (2009 Moringa oleifera has higher fungitoxic effect than C. odorata. While Moringa oleifera extracts completely controlled the mycelial growth of G. candidum; with $100 \%$ inhibition at 100 mg mLG1.

Moringa oleifera extract also showed progressive retardations of the mycelial growth of M. micheli and R. stolonifer (Oluduro,2012) obtained fungal inhibitory activities with extracts of M. oleifera as was observed in this study confirming the antifungal potency of the extracts. Extracts from M. oleifera at $100 \mathrm{mg} \mathrm{mLG} 1$ concentration was the closest to benlate at $20 \mathrm{mg} \mathrm{mLG1}$ which is the standard fungicide for rot control in cucumber. The disparity in the concentration of leaf extracts and benlate was that the extract was in crude form while benlate was refined. Therefore, leaf extracts required higher concentration to work efficiently.

\subsection{Phytochemical Constituents of Plants Used as Control Against Rot Organism}

The inhibitory effects of plant extracts on mycelial growth of plant pathogenic fungi have been claimed to lie in their phytochemical constituents which include alkaloids, tannins, flavonoids, phenols, saponins, terpenoids among others (Anyasor et al., 2011). Phytochemical analysis shows that plants such as C. odorata contain alkaloids, tannins, flavonoids, phenols, saponins and terpenoids in while M. oleifera contained all the phytochemicals stated above except alkaloids. Anyasor et al. (2011) in his study was able to show the presence of terpenoids, tannins, saponins, anthraquinones, phenols and cardiac glycoside in extracts of C. odorata while Bamishaiye et al. (2011) also noted the presence of alkaloids, tannins, phenolics, saponins, flavonoids and steroids in extracts of M. oleifera. The fungicidal properties of the extracts hindered the mycelial development of the fungi by probably affecting their metabolism which may have resulted in their inability to use. The presence of phytochemicals in plants supports their use as antimicrobial agents. The fact that plant extracts from M. oleifera and C. odorata are used to control the rot of cucumber fruit makes them a possible substitute for synthetic fungicide. This approach to plant disease management is economically viable and poses little environmental risk.

\subsubsection{Alkaloids}

These are organic nitrogenous compounds that have complex molecular structures of good pharmacological activity thus, bitter in taste and mostly basic in nature (El-Olemylet al., 2013). These chemicals comprise up largest single class of secondary plant substances which contain one or more nitrogen atoms usually in combination as part of cyclic system. Alkaloids do not have an exact nomenclature but they are named as proto alkaloids, when they are without heterocyclic ring in their structures, pseudo alkaloids are those alkaloids with and without heterocyclic rings that are not derived from amino acids and the carbon skeleton is soprenoid, and true alkaloids, which are those that have heterocyclic rings in their structure. True alkaloids and photo alkaloids almost always have amino acids as their distal biosynthetic precursors and acetate is also incorporated in their structure. Alkaloids accumulate in actively growing tissues, epidermal and hypodermal cells, vascular sheath and latex vessels (Evans and Trease, 2009).

Alkaloids are usually colourless, often optically active substance, most are crystalline but few are liquid at room temperature e.g., nicotine (Kanoma, Muhammad, Abdullahi, Shehu, Maishanu \& Isah,2014). The alkaloid quinine for example is one of the prodominant bitter substances known, and is significantly bitter at molar concentration of 1 X 105. The most common precursors of alkaloids are amino acids. Many alkaloids are terpenoids in nature and some (e.g Solanine, the steroidal alkaloid of the potato) are the best considered from the biosynthetic point of view as modified terpenoids. Others are aromatic compounds e.g., colchicine. Alkaloids are 
rich in the angiosperms families and are generally absent or infrequent in the gymnosperms, ferns and lower plants (Evans and Trease, 2009).

\subsubsection{Tannins}

The term tannins denote substances present in plant extracts which are able to combine with proteins of animal hides and convert them into leather. Tannins are widely distributed in plants and occur in solution in the cell sap, often in distinct vacuoles. Tannins are readily soluble in water or alcohol, given as stringent solution that is useful in medicine. They are also used with ferric chloride in compound inks of greenish black to bluish black colours. There are two main groups of tannins; namely, true tannins and pseudo tannins. The true tannins are complex phenolic compounds (Kanoma, Muhammad, Abdullahi, Shehu, Maishanu \& Isah,2014). They display the general properties of tannins and are precipitated by gelatin in a $1 \%$ aqueous solution. True tanninsare further classified into two main classes; hydrolysable (pyrogallol) tannins (Ellagitannin and gallitannin), and condensed tannins (catechol and catechin). The pseudo tannins (gallic and ellagic acids) are simple phenolics that give some of the tests of tannins, but are not precipitated by gelatin.

Tannins have a therapeutic value as astringents, since; they are able to precipitate proteins. Through this effect they can be used to stop hemorrhage and to treat diarrhea as well as local burns (EL-Olemylel al., 2013).

2.2.3 Flavonoids

These are the largest group of naturally occurring phenols and they occur in the plant both in the free state and as glycosides. The flavonoids group may be described as a series of C6-C3-C6 compounds (Kanoma, Muhammad, Abdullahi, Shehu, Maishanu \& Isah,2014). The majority of flavonoids are characterized by containing linkage of the three-carbon chain with one of the benzene rings. Flavonoids are widely distributed in nature, but are more common in the cell sap of higher plants. They usually constitute the yellow, red and blue pigments of flowers and fruits. Flavonoids are important in many industries such as fermentation of tea, tannins of. Some flavonoids have fungicidal properties and are found to protect the plant against attack by pest and parasite (Evans and Trease, 1999). 2.2.4 Saponin

Saponin is one of the groups of glycosides found in many plant species with known foaming properties when mixed with water, allowing the formation of small stable bubbles. The amount of foam created by the crushed plant samples shaken with water in a jar is a good indication of the amount of saponins present. Saponins are normally broken down in the digestive system and are toxic when absorbed into the blood stream (Kanoma, Muhammad, Abdullahi, Shehu, Maishanu \& Isah,2014).

They are used in modern times in the manufacture of fire extinguisher foam, tooth paste, shampoos, liquid soap and cosmetics. It is also used to increase the foaming of beer soft drink. As glycosides they are hydrolysed by acids to give an aglycone (sapogenin) and various sugar and related uronin acids. The steroidal saponin and pertocyclicterpenoids have a glycosydial linkage at -C3 and have a common biogenetic origin through malvalonic acid and isoprenoid unit (Evans and Trease, 2009).

2.2.5 Glycosides

Glycosides are non-reducing substances, which on hydrolysis with reagents or enzymes yield one or more reducing sugars among the products of hydrolysis. The non-sugar part of the molecule is called the aglycone or genin, and the sugar component, the aglycone. The usual linkage between the sugar and aglycone is an oxygen linkage, connecting the reducing group of a sugar and an alcoholic or phenolic hydroxyl group of the aglycone. Such glycosides, sometimes called O-glycosides, are the most numerous ones found in nature. Other glycosides however occur, e.g., S-glycosides and N-glycosides in S-glycosides, e.g. Sinirin, where the sugar is linked to the thiol group of the aglycone (Kanoma, Muhammad, Abdullahi, Shehu, Maishanu \& Isah,2014). In n-glycosides (e.g., streptidine moiety of streptomycin and glucosamine), the sugar is linked to the amino group of the aglycone (Ogbonnaya,2016). There are also c-glycosides (e.g., barbalion) in which the sugar is linked to the aglycone by a carbon-to-carbon bond. All naturally occurring glycosides are of the $\beta$-type, although the $\alpha$-linkage is found in some carbohydrates such as sucrose, glycogen and starch (Evans and Trease, 2009).

Glycosides occur widely in nature and occur in low concentration in nearly all plants. They occur not only in angiosperms but also in lower plants e.g., in streptomyces species. Glycosides are found in all parts of the plant, in roots, bark, leaves, flowers, fruits and seeds. Much plant pigments responsible for the colour of flowers and fruits are glycosides. Glycoside formation may well be a method of storing certain organic compounds e.g., phenols. It is also suggested that, some glycosides have a role of defence against the invasion of the tissue by micro-organisms subsequent to wounding, since many agylcones are aseptic and hence bactericidal in character. Plant glycosides that are currently used in medicine, though not larger in number, are important drugs. Glycosides of medicinal plants may be used as cardial stimulants (e.g., digitoxin and quabian or laxatives) Sinnosides and barbaloin or local irritants e.g., sinigrin or analgesics (silicon) and against capillary frugility (hesperidin) (Evans and Trease, 2009; Obia,2014).

\section{Material and Method}

The plants M.olerfera and C.odorata were collected from okpuno village in Awka north Local government area of 
Anambra state. The plants were transported to Maeve research laboratory and identified by Botanist Omaka before phytochemical analysis and anti-fungi analysis.

\subsection{Reagents}

The reagents used are; SDA culture media, Hydrochloric, Meyer's reagent, Wagner's reagent iron III chloride, sodium hyofroxide, ferric chloride, Conc teteraoxosuilphate (vi) acid, Fehling's solution, ethanol, acetic anhydride and methanol.

\subsection{Equipment's}

The equipment used in the study are; test tube, test tube rack, dropper, $250 \mathrm{ml}$ beaker, petti dish, distil water, spatula, weighing balance, cotton wool, cork borer, oven, Bunsen burner, measuring cylinder, inoculating loop, autoclave, $500 \mathrm{ml}$ boiling flask, electric blender and Soxhlet extractor

\subsection{Preparation of Culture Media}

Twenty grams of SDA was weighted into $250 \mathrm{ml}$ beaker. To the beaker containing the SDA, hundred milliliters of distil water was then added to the media, stirred and made air tight using cotton wool. The beaker and the mixture in it were transferred into an autoclave and autoclaved for 15 minutes at the $1210 \mathrm{c}$ at a pressure of $15 \mathrm{psi}$. The media was letter pour into a petri dish and allowed to cool down after autoclaving. A small portion of yam infected with rot organism was inoculated into the petri dish containing the media. The inoculated media was covered and kept for 72 hours for growth of microorganism.

\subsection{Isolation and Sub-culturing}

The cultured organism was isolated using inoculating loop and subculture to get a pure culture of the organism.

\subsection{Pathogenicity Test}

The test was carried out using the methods of Okigbo and Emeka, (2010) method. In this method, the isolated fungi were introduced into a healthy yam tuber and observed for a week to actually ascertain if these organisms are the cause of rot in yam tuber.

\subsection{Preparation of Extracts}

The plant was dried under room temperature of $25 \pm 10 \mathrm{c}$ for 7 days. The dried plant sample were grounded in electric blender. $100 \mathrm{~g}$ of each of the plant samples were weighed into two different $500 \mathrm{ml}$ boiling flack containing ethanol and methanol solvent respectively and allowed for 24 hours. The mixtures were filtered using muslin cloth. Soxhlet extractor was then used to extract the phytochemical component of the sample after which the extracted phytochemical was further subjected to analysis.

\subsection{Phytochemical Screening of Plant Extracts (Qualitative phytochemical screening)}

Phytochemical screening was conducted to qualitatively determine the presence or absence of the following secondary metabolites that is, Alkaloids, Tannins, Flavonoids, Saponins, Anthraquinones, Glycosides, Saponins glycosides, Cardiac glycosides using the method outlined by (Evans \& Sofowora, 1993; El-olemyet al., 1994; Siddiqui and Ali, 1997; Trease, 1999).

\subsubsection{Alkaloids}

Exactly $0.5 \mathrm{~g}$ of each extract were stirred with $10 \mathrm{~cm} 3$ of $10 \%$ hydrochloric acid and allowed to stand overnight and then divided in to two parts for the following test.

- 2 drops of Meyer's reagent were added to $1 \mathrm{~cm} 3$ of the extracts, appearance of a creamy precipitate was taken as the evidence of the presence of alkaloids.

- b. 2 drops of Wagner's reagent were added to $1 \mathrm{~cm} 3$ of the extracts. A reddish-brown precipitate observed in each test tube indicated the presence of alkaloids (Evans \& Trease, 1999).

\subsubsection{Tannins}

Few drops of iron (iii) chloride (\%w/v) solution were added to $3 \mathrm{ml}$ of the extracts in a test tube followed by shaking. A dirty green or dark blue coloration confirmed the presence of tannins (Evans \& Trease, 1999).

3.7.3 Flavonoids

One milliliter of the extracts was treated with $1 \mathrm{ml}$ of dilute $\mathrm{NaOH}$. The presence of a cloudy precipitate confirms the presence of flavonoids. (Evans and Trease, 1999).

3.7.4 Saponins

Five $(5 \mathrm{ml})$ of distilled water was added to $2 \mathrm{ml}$ of the extracts in a test tube and shaken vigorously. The formation of foams or stable frothing following the shaking indicated the presence of saponins. (Evans \& Trease, 1999).

3.7.5 Test for cardiac glycoside

Keller-killiani's test: To one of extract $2 \mathrm{ml}$ of 3.5\% ferric chloride solution was added and allowed to stand for 
one minute. $1 \mathrm{ml}$ of conc. $\mathrm{H} 2 \mathrm{SO} 4$ was carefully poured down the wall of the tube so as to form a lower layer. A reddish-brown ring at the interface indicated the presence cardiac glycoside.

3.7.6 Anthraquinones

Two milliliters of $10 \%$ hydrochloric acid were added to the extract in a test tube and boiled for about two minutes. Equal amount of chloroform was added to the test tube and vortexes twice, the chloroform layer was pipette out and then equal volume of $10 \%$ ammonia was added. A pinkish red colour observed in upper layer indicated the presence of anthraquinones (Evans and Trease, 1999).

3.7.7 Glycosides

$2.5 \mathrm{ml}$ of $50 \%$ sulphuric acid was added to $5 \mathrm{ml}$ of the extract in a test tube. The mixture was heated in boiling water for 15 minutes, cooled and neutralized with $10 \% \mathrm{NaOH}$. Then $5 \mathrm{ml}$ of Fehling's solution was added and mixture was boiled. A brick-red precipitate was observed which indicate the presence of glycosides (Evans and Trease 1999).

3.7.8 Saponin glycosides

To $2.5 \mathrm{ml}$ of the extract was added $2.5 \mathrm{ml}$ of Fehling's solution A and B. A bluish green precipitate showed the presence of saponin glycosides (El-Oley et al.,1994).

\subsection{Antifungal Bio-Assay}

The methods of Shiriki et al. (2015) were employed using the plant extracts prepared above. $2 \mathrm{ml}, 4 \mathrm{ml}, 6 \mathrm{ml}$ and $8 \mathrm{ml}$ of the plant extract were pipetted into labelled sterile petri dishes containing the pure culture of the fungi respectively. Inhibition zone of the microorganism was evaluated against the yam tuber rot. The observations were recorded in terms of radial growth of the test fungi on the medium with and without extracts and results were analyzed on the basis of percentage growth inhibitions of test fungi. The inhibition of fungal growth on SDA medium was used to quantify the toxicity of extracts. Percentage growth inhibition for 5 days was calculated.

$\%$ growth inhibition $=\quad R 1-R 2 \times 100$

$$
R 2
$$

Where $\mathrm{R} 1=$ is the furthest radial distance of pathogens in control plates

Where $\mathrm{R} 2$ = is the furthest radial distance of pathogens in extract (treated) plates. The inhibition percentage was determined as a guide in selecting the minimum inhibition concentration (M.I.C) that will be effective in controlling the rot causing fungi.

Extracts were rated for their inhibitory effect using a scale.

$<0 \%$ inhibition (not effective)

$>0-20 \%$ inhibition (slightly effective)

$>20-50 \%$ inhibition (moderately effective)

$>50-100 \%$ inhibition (effective) and 100\% inhibition (highly effective)

\subsection{Identification}

The methods of Shiriki et al, (2015) and Chesbrough, (2000) were used for the various tests and examinations. The isolated fungi organism was fixed on a slide and viewed under microscope. Identification of fungi isolates was carried out using by matching the physiological and anatomical structure of the viewed fungal with those on the fungal identification kit.

\subsection{Statistical Analysis}

The data collected were subjected to one-way analysis of variance (ANOVA) to ascertain the level of significance at $0.05 \%$ of the treatment given to the fungi growth. 


\section{Results}

Table 4.1.1: Phytochemical Properties of Chromoleana odourata and Moringa oleiferia

\begin{tabular}{ccc}
\hline Phytochemical & C.odorata & M. oleifer \\
\hline Alkaloids & + & + \\
Flavonoids & ++ & + \\
Glycosides & + & - \\
Steroids & + & + \\
Terpenes & + & + \\
Saponins & ++ & - \\
cardiac glycoside & - & + \\
Anthraquinones & - & + \\
Saponin glycosides & ++ & + \\
volatile oils & ++ & + \\
Tannins & ++ & + \\
Test for Resins & - & + \\
Acidic compound & + & \\
\hline
\end{tabular}

Key: Moderately present $(++)$; Present in excess $(+++) ;=$ present in little quantity $(+)$; Absent (-)

Table 4.1.1: shows that C.odorata contain alkaloid, Flavonoids, Glycosides, Steroids, Terpenes, Saponins, Saponin glycosides, volatile oils, Tannins and Acidic compound while M. oliefera contain Alkaloids, Flavonoids, Glycosides, Terpenes, Saponins, Anthraquinone, Saponin glycosides, volatile oils, Tannins, Resins, and Acidic compound. These phytochemical properties of the plant make the plant to possess antimicrobial properties. Table 4.1:2 Anti-Microbial Effect of C.odorata and M.oliefera Extract

\begin{tabular}{llll}
\hline Microorganism & M.oliefera & C.odorata & Control \\
\hline Yeast & $7.90 \pm 0.65^{*}$ & $7.70 \pm 0.69^{*}$ & $3.6 \pm 0.13$ \\
Aspergilius spp & $9.73 \pm 1.03^{*}$ & $11.2 \pm 0.92^{*}$ & $3.2 \pm 0.33$ \\
Fusarium & $9.17 \pm 1.17^{*}$ & $13.35 \pm 1.34^{*}$ & $4.8 \pm 1.00$ \\
Mould fungi & $8.27 \pm 1.27$ & $15.80 \pm 1.04^{*}$ & $5.5 \pm 0.12$ \\
\hline
\end{tabular}

*Treatment that has Significant Effect.

Table 4.1.2: shows that extract of M.oleifera has significant inhibitory effect on E.coli as compared to the control and no inhibition observed on Aspergilius spp, Fusarium and Mould fungi. On the other hand, C.odorata was observed to inhibit the growth of yeast, Aspergilius spp, Fusarium and Mould fungi as compared to the control treatment. This result implies that the extract of C.odorata and M.oleifera has more inhibition effect on microorganism such as Aspergilius spp, Aspergilius spp, Fusarium as compared to the control experiment.

Table 4.1.3 Two- Way Analysis of Variance (ANOVA)

\begin{tabular}{crlllll}
\hline \multicolumn{2}{c}{ Source of Variation } & \multicolumn{1}{c}{ DF } & SS & MS & F & P \\
\hline ORGANISM & 3 & 21.219 & 7.073 & 0.941 & 0.012 \\
EXTRACT & 2 & 23.160 & 11.580 & 1.541 & 0.024 \\
Residual & 2 & 15.027 & 7.513 & & & \\
Total & 7 & 58.540 & 8.363 & & & \\
\hline
\end{tabular}

$0.05 \%$ Level of significance.

Table 4.1.3: indicated that the treatments are significant on the organisms at $\mathrm{p}<0.05 \%$ level of significance.

Table 4.1.4: Least square means for Organism

\begin{tabular}{cl}
\hline Group & Mean \pm SD \\
\hline Yeast & $7.949 \pm 2.359$ \\
Aspergilius spp & $9.431 \pm 2.175$ \\
Fusarium & $11.409 \pm 2.359$ \\
Mould fungi & $12.184 \pm 2.359$ \\
\hline
\end{tabular}

\section{LSD $0.05 \%$}

Table 4.1.4: shows that mold fungi was highly inhibited by the extract followed by Fusarium, Aspergillus and least in E-coli. 
Table 4.1.5 Least Square Means for Extract

\begin{tabular}{cc}
\hline Group & Mean \pm SD \\
\hline Control & $8.176 \pm 1.769$ \\
M.oliefera & $10.543 \pm 3.626$ \\
C.odorata. & $12.013 \pm 1.371$ \\
\hline
\end{tabular}

\section{LSD0.05\%}

Table 4.1.5: indicates that C.odorata has the highest inhibition effect on the organisms followed by that of M.oleifer and least in control.

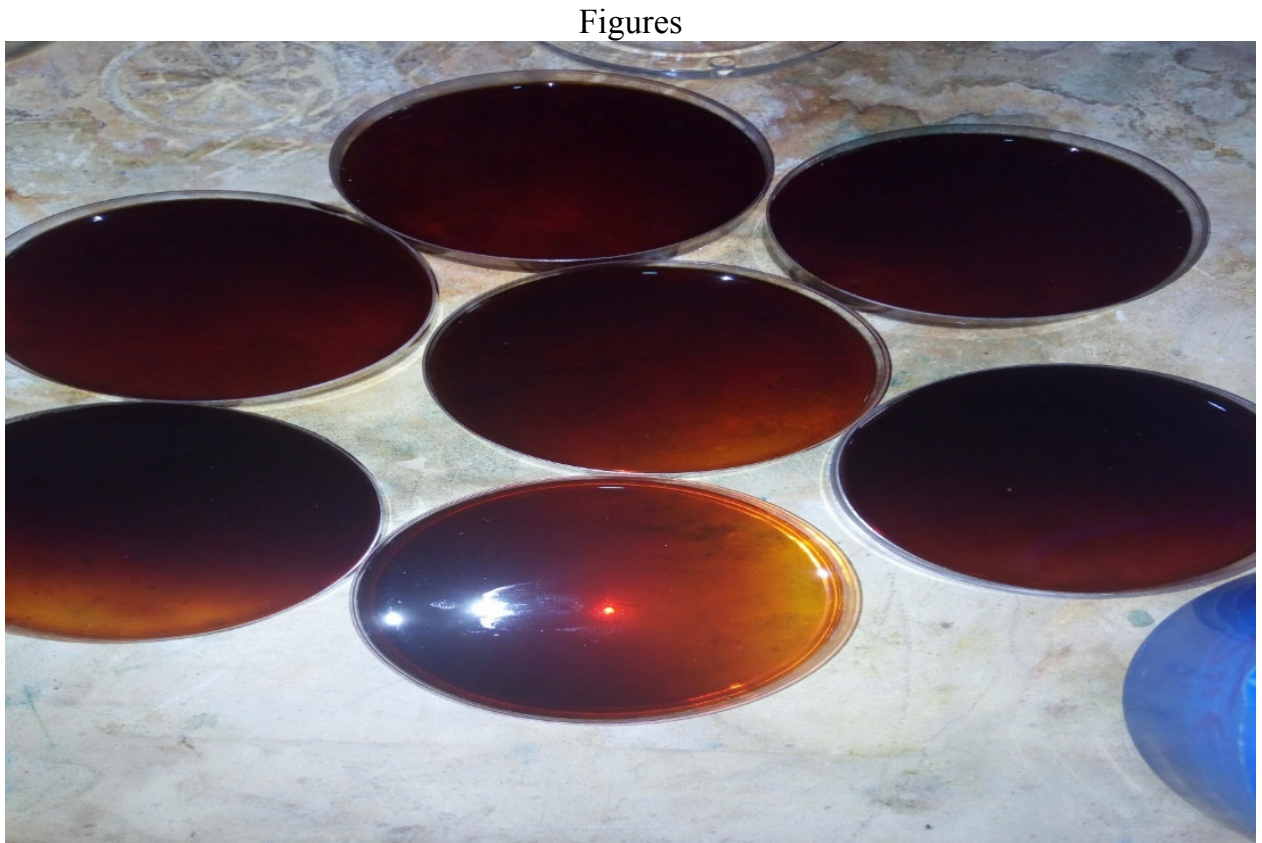

Plate 1: Prepared Culture Media

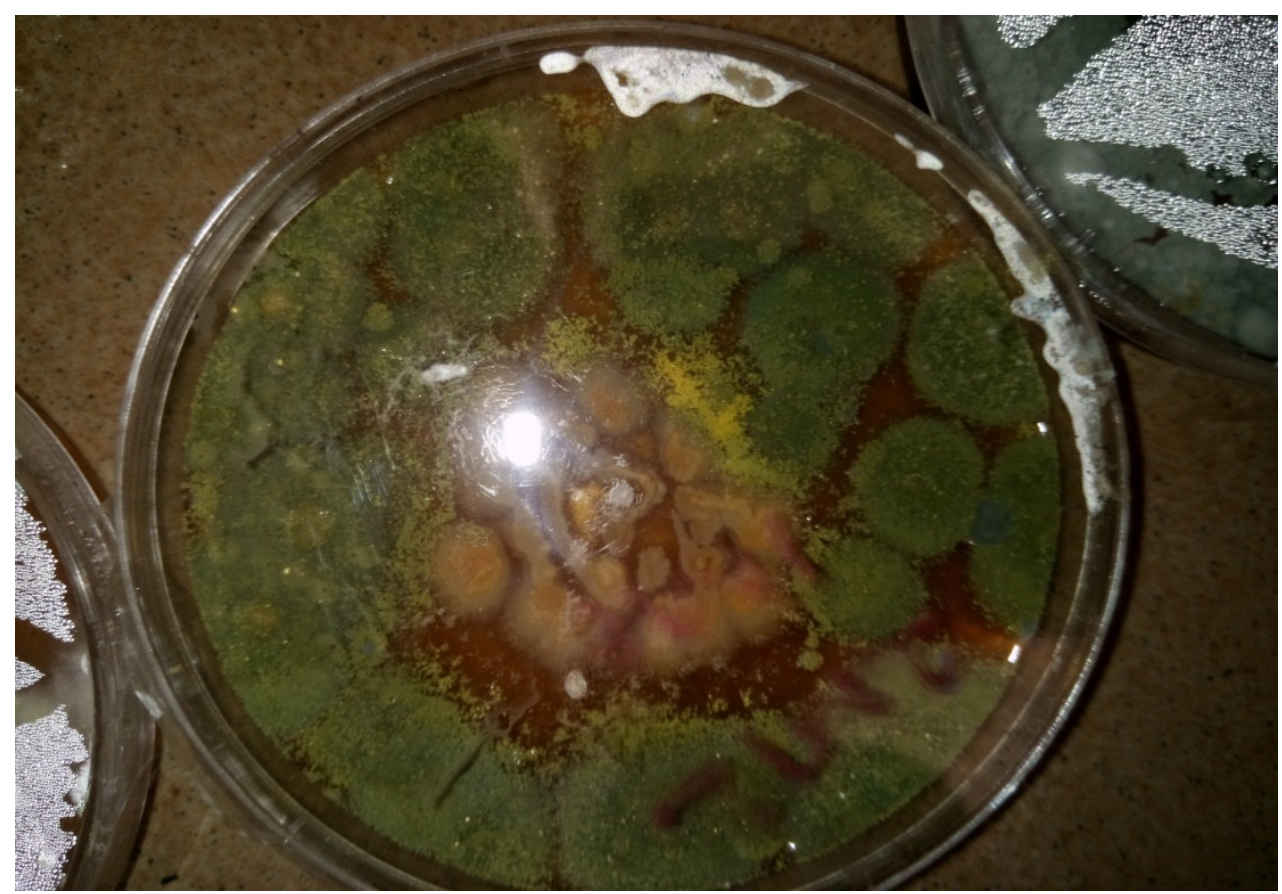

Plate 2: Colonies of Fungi 


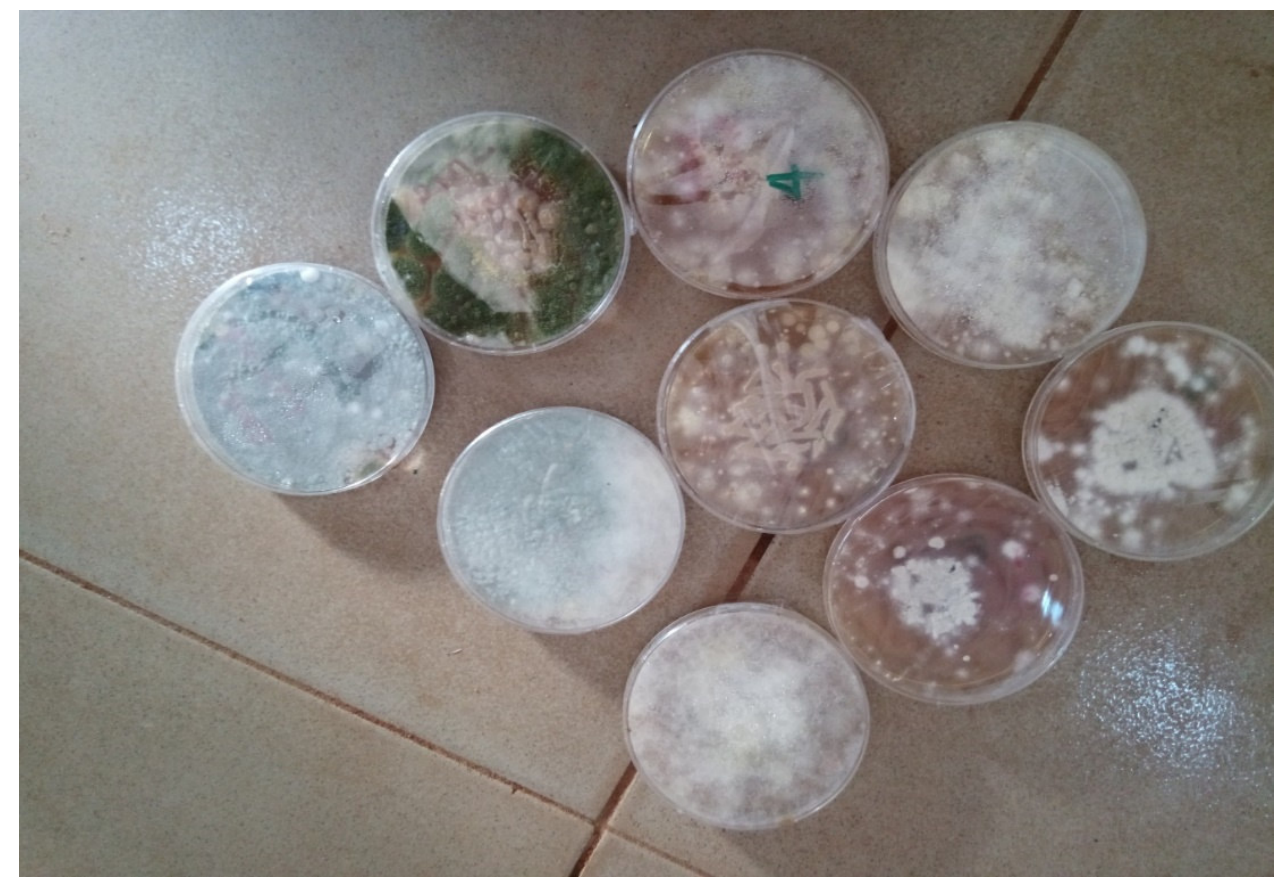

Plate 3: Pure Culture of Fungi

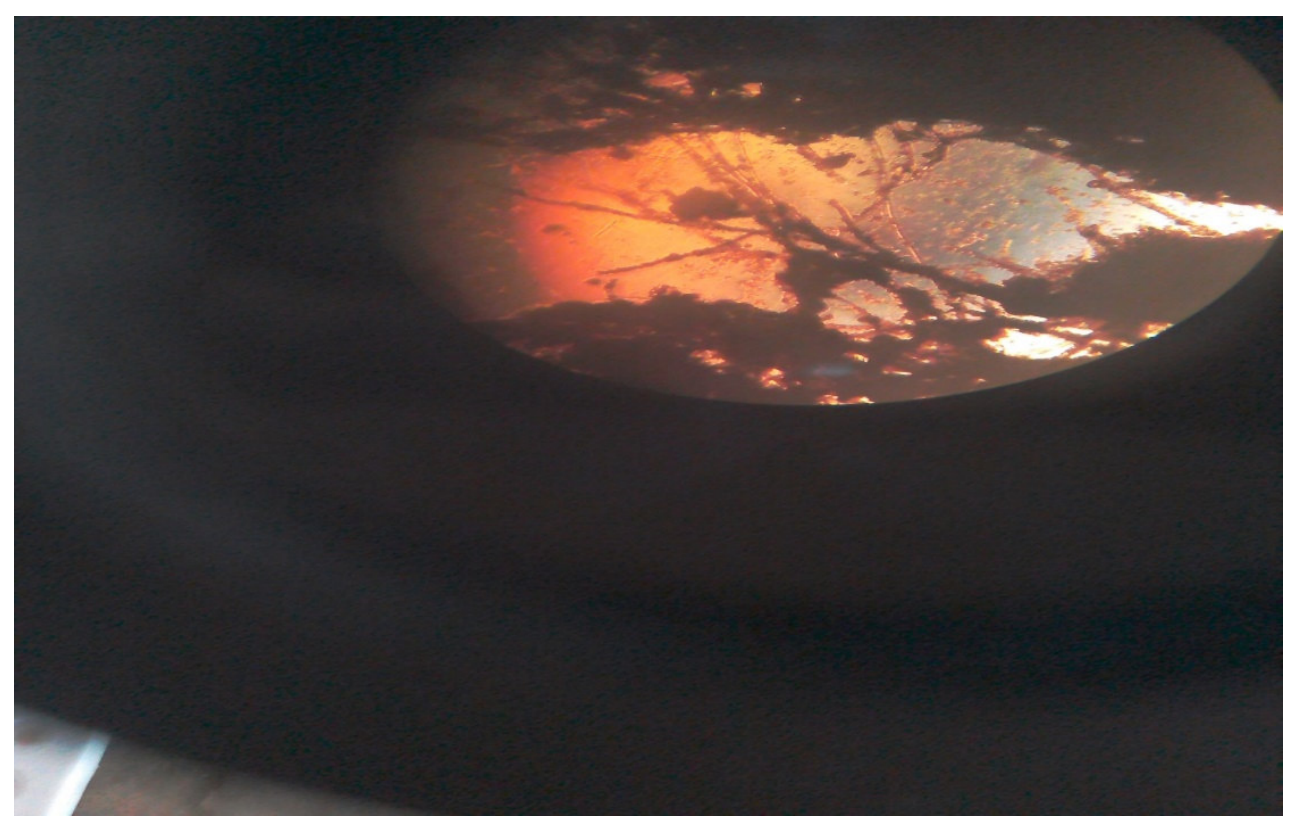

Plate 4: Microscopic view of fusarium spp

Magnification 10x 


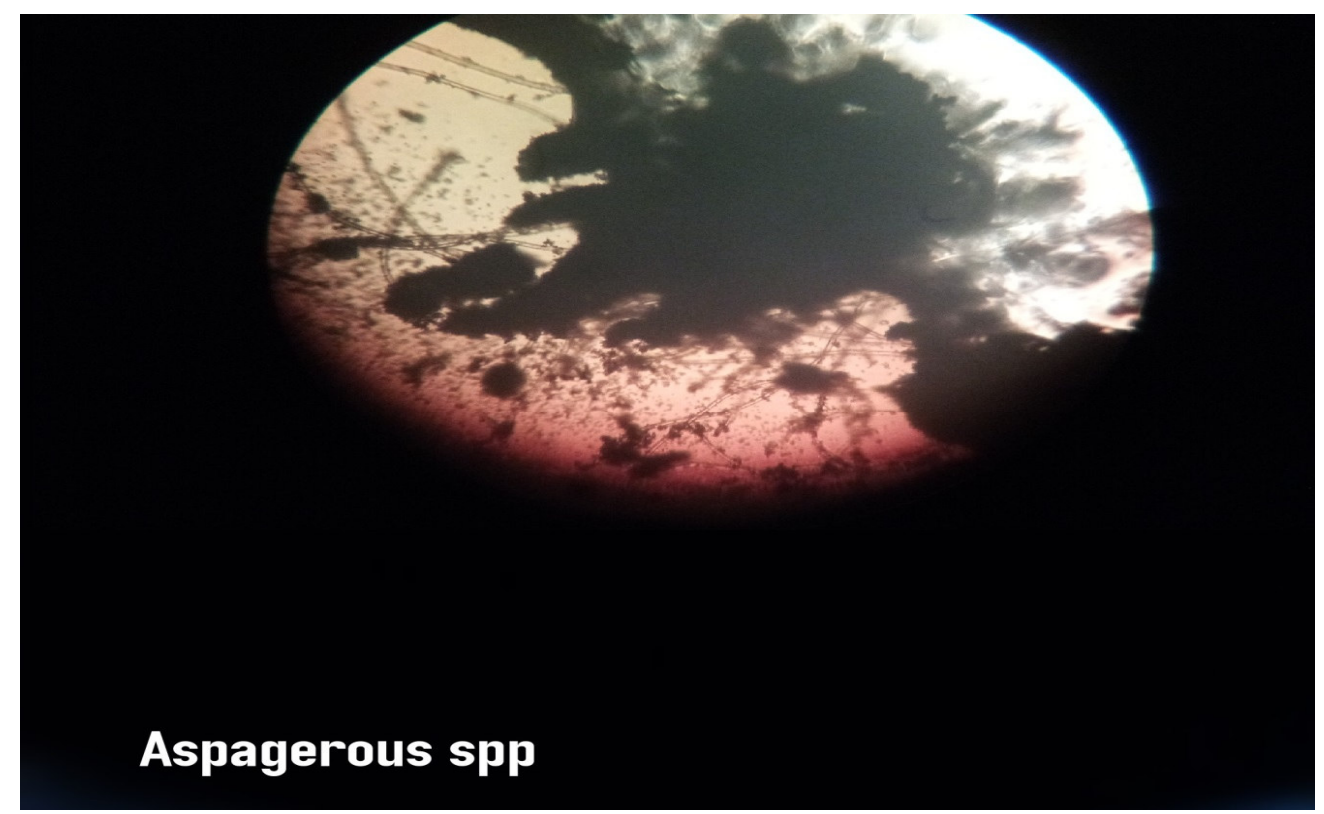

Plate 5: Microscopic view of Aspergillus spp

Magnification 10x

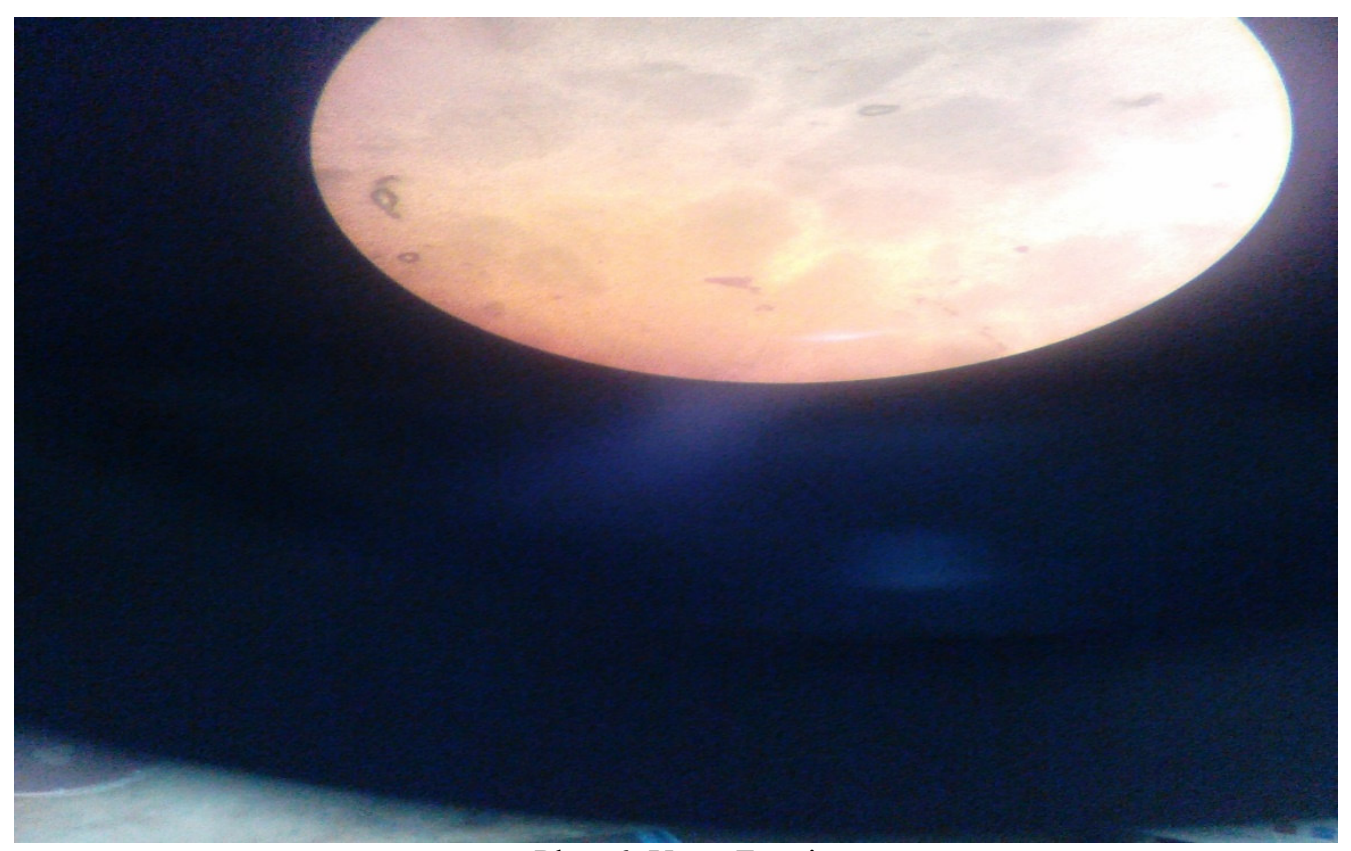

Plate 6: Yeast Fungi

\section{Discussion, Conclusion and Recommendation}

\subsection{Discussion}

Finding from the study showed that C.odorata contain alkaloid, Flavonoids, Glycosides, Steroids, Terpenes, Saponins, Saponin glycosides, volatile oils, Tannins and Acidic compound while M.oliefera contain Alkaloids, Flavonoids, Glycosides, Terpenes, Saponins, Anthraquinone, Saponin glycosides, volatile oils, Tannins, Resins, and Acidic compound. The phytochemicals are is various concentration, some are excessively present and some others moderately present. These phytochemical are noted to give C. odorata and M.oliefera the medicine capacity in inhibiting the growth of microorganisms. this finding corroborates with the finding of Oluduro, (2012) who said that Moringa oleifera extract shows progressive retardations of the mycelial growth of M. micheli and R. stolonifer. The finding also indicated that the phytochemical properties in these two plants has inhibitory effect against Aspergilius spp, Fusarium, yeast and Mould fungi. Study also showed that C.odorata and M.oliefera Inhibit the growth of yeast, Aspergilius spp, Fusarium and Mould fungi as compared control(penicillin) treatment. This finding agrees with the finding of Omaka (2012) who in his study reported that Chromolean odorata has inhibitory 
effect on the growth of rot organism such as fusarium spp and Aspergillus spp the finding also agree with the finding of Suleiman and Emua (2009) observed toxicity of plant extracts such as Moringa oleifera has higher fungitoxic effect on fungi rot organisms. The finding also indicated that organisms such as aspergillus niger and Fusarium oxysporum are found associated with yam rot and are responsible for the rot in yam. This agree with the finding of Chiejina \& Onaebi (2016) who reported that organisms associated rot in tubers and fruits are Geotrichum candidum, Mucor micheli, Rhizopus stolonifer, Aspergillus niger and Fusarium oxysporum.

\subsection{Conclusion}

The study has shown that plant extracts such as C.odorata and M.oliefera has strong antimicrobial effect against rot fungi of yam. Evidence from pathogenicity test also confirmed the rot fungi such as Aspergilius spp, yeast and Fusarium among others as the rot fungi associated with yam that are responsible for rot. Therefore, from the findings, its now more evident that C.odorata and M.oliefera can be used to control rot fungi of yam.

\subsection{Recommendation}

Based on the findings, it is recommended that farmers should use bio-fungicide from C.odorata and M.oliefera in the control of yam rot fungi.

\subsection{Suggestion for further Study}

Further Study should be carried out on the effect of other plant extract on the control of yam rot organism.

\section{References}

Shiriki, D., Ubwa, S.T. and Shambe, T. (2015) Isolation of Nine Microorganisms from Rotten Dioscrea rotundata (White Yam) and Antimicrobial Sensitivity Test with Five Plant Extracts. Food and Nutrition Sciences, 6, 825-835.

Chesbrough, M. (2000) District Laboratory Practice in Tropical Countries. Low Price Edition, Cambridge University Press, Cambridge, 62-70.

Okigbo, R.N. and Emeka, A.N. (2010) Biological Control of Rot-Inducing Fungi of Water Yam (Dioscorea alata) with Trichoderma harzianum, Pseudomonas syringae and Pseudomonas chlororaphis. Journal of Stored Products and Postharvest Research, 1, 18-23. 